\title{
O estágio curricular supervisionado na experiência brasileira e internacional
}

\author{
Marina Cyrino \\ Samuel de Souza Neto \\ Universidade Estadual Paulista | Rio Claro
}

\section{Resumo}

artigo insere-se na temática do Estágio Curricular Supervisionado (ECS) e na problemática de um modelo profissional de formação docente. $O$ objetivo foi apresentar e compreender o ECS no Brasil, Canadá, Estados Unidos, França, entre outros. A pesquisa foi bibliográfica e documental, qualitativa com a análise de conteúdo. Selecionamos experiências que envolviam a relação universidade e escola, valorizando o papel do professor de escola na formação docente. No Brasil, essas iniciativas surgiram de universidades; e, nas experiências internacionais, as iniciativas emergem das políticas públicas nacionais. Nesse contexło, assinala-se para a questão da formação sob a perspectiva da profissionalização docente, sendo necessário um esforço das políticas públicas e dos cursos de formação docente.

86 Palavras-chave: Estágio curricular. Profissionalização docente. Escola e universidade.

\section{The supervised practical training in Brazilian and international experience}

\begin{abstract}
This article is inserted in the field of teacher education, centering the discussions in Supervised Practical Training (SPT) and the issues of training model placed in the teaching profession. The aim of this qualitative study was to present the SPT in Brazil, Canada, United States, France and others, from a bibliographic and documental, qualitative research and analysis content. We selected the practical training experiences that take for granted the university and school relationship to value the role of school teacher in teaching education. In Brazil, these initiatives have emerged from universities; whereas, in the international experiences, the initiatives have emerged from national public policies. We pointed to the teaching professionalization and concluded that the Brazilian public teacher education policies should consider the practice as the locus of teacher education.
\end{abstract}

Keywords: Supervised practical training. Teacher professionalization. Schooland university. 


\section{La práctica pedagógica profesional la experiencia brasileña e internacional}

\section{Resumen}

El artículo trata sobre tiempo de prácticas profesionales y en la problemática de un modelo de formación situado en la profesión docente. El objetivo fue presentar y comprender las prácticas profesionales en Brasil, Canadá, Estados Unidos de América, Francia, entre otros. La investigación fue bibliográfica y documental, cualitativa con la técnica de análisis de contenido. Se Seleccionaron experiencias involucrando la relación universidad y escuela, valorando el papel del profesor de escuela en la formación del profesorado. En Brasil, estas iniciativas surgieron en la universidad $y$, en el campo internacional, las iniciativas emergen de las políticas públicas nacionales. En este contexto, se señala a la cuestión de la formación desde la perspectiva de la profesionalización del profesorado, siendo necesario un esfuerzo de las políticas públicas y de los cursos de formación docente. Palabras-clave: Practica profesional. Profesionalización del profesorado. Escuela y universidad.

\section{A problemática em questão...}

artigo trata da formação inicial de professores tendo como foco as orientações sobre o estágio curricular, a parceria entre universidade e escola e a figura do professor da escola que recebe estagiários (professor-colaborador, cooperante, associado ou tutor/mentor/na experiência brasileira e internacional (Canadá, Estados Unidos, França, Portugal, Inglaterra, dentre outros).

$\bigcirc$ contexto de investigação paira sobre as políticas docentes (normativos legais) e as experiências no campo de estágio que apontam para uma área de conhecimento emergente, trazendo subjacente a ela o Movimento de Profissionalização do Ensino que perpassa as reformas políticas docentes em âmbito internacional e nacional.

Esse movimento tem como proposta tornar a docência uma profissão, revendo todo o processo de formação inicial e continuada com base na carreira docente. A profissionalização do ensino tem como um de seus marcos a reforma educacional ocorrida nos EUA nos anos 1980, quando decanos de 
cinquenta universidades, através do Relatório "Tomorrow's Teacher", propuseram uma mudança na formação de professores, estruturando-a a partir da carreira docente em que se valorizava o professor profissional e o profissional de carreira, enfim, o expert (HOLMESGROUP, 1986). Ao centralizar a reforma na "carreira docente" e não na "formação inicial de professores", o Grupo Holmes introduziu um novo paradigma pautado na ideia de profissão proveniente da cultura anglo-americana. Tal concepção é tratada, apenas, em alguns grupos acadêmicos no Brasil, pois signatário do Modelo Continental Europeu (SOUZANETO, 1999), de maneira geral, não faz uma distinção clara entre oficio e profissão, sendo vistos como sinônimos.

No Canadá francês(Quebec), essa reforma ocorreu no início dos anos 90, adotando como currículo o modelo profissional: uma formação em alternância entre o meio universitário e o meio escolar, do primeiro ao quarto ano com o estágio supervisionadoa partir do primeiro ano, colocando a prática como o "coração" da formação. Do mesmo modo, a profissionalização do ensino também perpassou o contexto da França na década de 90, criando os Institutos Universitários de Formação de Professores (IUFM) e propondo um modelo profissional para a preparação de professores da escola básica,

88 voltado para a prática e tendo a escola como lócus da formação. Assim, em ambos os casos, os docentes da escola são considerados corresponsáveis pela formação dos futuros professores, pois auxiliam no acompanhamento dos estágios nas escolas de maneira formal, sistematizada e remunerada, ou seja, há uma política docente envolvida.

Nesse percurso, observa-se que o estágio supervisionado é uma das estratégias presentes nos currículos das licenciaturas e parte integrante e imprescindível na formação inicial docente por ter,entre as suas finalidades, auxiliar o licenciando na passagem de aluno/estudante a professor.

Essa relação envolve um trabalho de articulação com a direção e coordenação da escola, orientação do professor dessa mesma instituição (professor-colaborador), a supervisão do professor da universidade/faculdade (professor supervisor). Portanto, essa tríade prescinde de uma integração entre Universidade, Professor Supervisor, Escola e Professor-Colaborador, sendo referendada por pesquisadores da área em recortes diferentes no que se refere ao professor-colaborador (BENITES, 2012 ), parceria com professores da escola (SARTI, 2009), imersão do estagiário na escola (GIGLIO, 20 1 0), compromisso da escola na formação do futuro professor (CYRINO, 2012) dentre outros. 
No entanto, nas atuais políticas docentes brasileiras, essas questões não são consideradas, principalmente no que diz respeito aos atores que envolvem o processo de estágio: a equipe gestora da escola e o professor-colaborador ou parceiro. Estes não são encarados como formadores pela legislação vigente (BRASIL, 2008). Dessa forma, também não recebem uma formação específica para orientar estagiários, ficando essas questões a cargo dos professores universitários responsáveis pelos estagiários.

Na contramão da ordem hegemônica, há algumas experiências brasileiras que buscam atravessar essa barreira e, dentro das possibilidades, estabelecem vínculos com escolas, oferecem formação aos docentes que receberão estagiários, além de outras perspectivas. Em âmbito internacional,essas questões são apresentadas a partir do Ministério da Educação que há em todos ospaíses, ou órgão responsável, os quais estabelecem diretrizes que permitem às universidades e escolas realizar a formação dos professores de forma conjunta e sistematizada, ou ainda, auxílios financeiros aos professores da escola que recebem estagiários, sem excluir outras possibilidades. É claro que, nesses países onde as possibilidades de estágio encontram-se mais sedimentadas, houve um longo processo de lutas, conquistas, retrocessos, avanços.

Com base nesses apontamentos, o presente estudo objetiva apresentar e compreender o contexto do estágio curricular supervisionado no Brasil e, em âmbito internacional, a partir de uma pesquisa bibliográfica e documental, tendo como referência o estágio curricular, a parceria entre universidade e escola e a figura do professor da escola que recebe estagiários. Os documentos dizem respeito à legislação, diretrizes e normativos que estabelecem um norte para a formação de professores ou especificamente para o estágio. Na pesquisa bibliográfica, buscamos em bases de dados artigos que pudessem explorar experiências de estágio, bem como livros ou anais de reuniões científicas que explicitassem essas questões.

A análise qualitativa de dados ocorreu sob a perspectiva da análise de conteúdo (LUDKE; ANDRÉ, 1986, p. 41), realizada "[...] a partir do exame dos dados e de sua contextualização no estudo". Este é caracterizado "como um método de investigação do conteúdo simbólico das mensagens [...]"; na unidade de análise (palavra, sentença, parágrafo ou o texto como um todo); na forma de tratar tais unidades e; na variação do enfoque da interpretação. Com essa compreensão, após a leitura e seleção do material, foram identificados eixos temáticos relativos à: compreensão do Estágio Curricular em diversos 
países; bem como experiências significativas que elucidam o Estágio como um campo de conhecimento.

$\bigcirc$ texto está organizado, inicialmente, com um breve histórico dos estágios na legislação brasileira a fim de compreender o modo como essa temática tem sido tratada pela política nacional. Na sequência, elucidamos experiências brasileiras que têm tentado romper com a linearidade dos estágios supervisionados através de uma estruturação mais dinâmica, bem como apresentamos a experiência internacional, visando contribuir com perspectivas, propostas e possibilidades. Por fim, concluímos o texto com algumas considerações a respeito do contexto apresentado.

\section{Os estágios curriculares: propostas de encaminhamento na trajetória da legislação brasileira}

$\mathrm{Na}$ legislação brasileira atual voltada para a educação e desenvolvimento profissional docente (BRASIL, 1996, 1997, 200 1, 200 la, 2002), encontramos direcionamentos para a formação inicial e continuada

90 de professores que abordam aspectos baseados em referenciais teóricos de grande renome na literatura.

No que tange à trajetória da formação inicial de professores, podemos destacar alguns normativos que apontam o estágio curricular supervisionado, como:o Parecer CFE 4.873 de 1975, que responsabilizava somente a universidade com relação à supervisão do estágio; a Lei nº.494, de 1977, que assinalava o estágio como uma experiência prática do currículo e dispunha sobre um vínculo não empregatício do mesmo e; o n Decreto 87.497, de 1982, que também apontava a responsabilidade da instituição de ensino na aprendizagem do estagiário, ou seja, a universidade.Porém, nessas e em outras legislações (BRASIL, 1946, 1962, 1969, 1975, 1977, 1982, 1984, 1994), a escola e os professores-colaboradores não são considerados enquanto formadores, sequer é prevista a sua preparação para receber e orientar os estagiários.Podemos encontrar encaminhamentos embrionários (BRASIL, 2008, 2002) a respeito de uma possível formação continuada do professor da escola que deve ser oferecida pela instituição de ensino superior (mais uma vez, a Instituição de Ensino Superior (IES) - é colocada à frente). Entretanto a fiscalização com relação ao cumprimento desses normativos nos cursos e 
instituições em nível superior é mínima, além das diferentes compreensões de estágio que perpassa.

Com a Lei de Diretrizes e Bases da Educação Nacional (LDBEN) n. 9.394/96, artigo 65, reafirmou-se a importância do estágio, propondo para todos os cursos de Licenciatura a Prática de Ensino com 300 horas, sendo alterada em 2001 e $2002^{1}$ com a proposta de 400 horas de Estágio Curricular Supervisionado, devendo ocorrer a partir da segunda metade do curso, com a incumbência de ser um período de aprendizagem da profissão que será exercida futuramente (BRASIL, 2002, 2002a). Neste formato, busca-se pensar a formação de professores a partir de um corpo de conhecimento: saberes, competências e habilidades, práticas de ensino, trazendo como novidade, o deslocamento do eixo da qualificação para a certificação profissional, entre outros aspectos, podendo-se confundir formar com formar-se.

estágio prescinde, então, de uma relação pedagógica entre um profissional reconhecido no local de trabalho e um aluno estagiário. A responsabilidade pela formação do estagiário não se restringe mais a um único professor da instituição formadora, sugerindo-se um coletivo, pois...

[... é é preciso que exista um projeto de estágio planejado e avaliado conjuntamente pela escola de formação inicial e as escolas campos de estágio, com objetivos e tarefas claras e que as duas instituições assumam responsabilidades e se auxiliem mutuamente, o que pressupõe relações formais entre instituições de ensino e unidades dos sistemas de ensino (BRASIL, 2001, p. 1).

A Resolução CNE/CP n 1 / de 2002 argumentou, no art. $12 \S \S 1^{\circ}$ e $2^{\circ}$ que, na matriz curricular, essa prática não poderia ficar reduzida a um espaço isolado ou restrita ao estágio e desarticulada do restante do curso. Deveria "[...] estar presente desde o início do curso [...]", permeando "[...] toda a formação do professor" (BRASIL, 2001 p.67). Desse modo, implicaria também uma mudança curricular, envolvendo ação-reflexão-ação (BRASIL, 20011 . 
$\bigcirc$ Estágio Curricular Supervisionado, atualmente, é orientado pela Lei $n^{\circ} 11.788 / 2008$ que propõe no art. $1^{\circ}$ que o estágio é o "[...] ato educativo escolar supervisionado [...] que visa à preparação para o trabalho [...]" e no parágrafo $2^{\circ}$ aponta o aprendizado de competências próprias da atividade profissional (BRASIL, 2008, p. 3), introduzindo uma maior estruturação entre instituição de ensino e a parte concedente do estágio.Destacamos, ainda, que essa lei é voltada para todo e qualquer tipo de estágio, não sendo específica para a formação de professores.

De maneira geral, os normativos legais do estágio resumem-se em orientações que estão mais preocupadas com a criação do vínculo não empregatício e de uma "vivência" do que com o estágio propriamente dito, proporcionalmente, no que diz respeito aos aspectos didático-pedagógicos. Nesse contexto, emergem algumas questões, como: quais as estratégias elaboradas pelas instituições ou professores universitários na ausência de sistematizações acerca do estágio? De que forma o estágio é organizado em outros países? No próximo tópico, explanaremos essas questões em âmbito nacional e internacional, destacando alguns países como França, Portugal, Canadá, Inglaterra, Estados Unidos, Brasil, entre outros.

\section{Estágio supervisionado: as experiências nacionais}

Na política docente brasileira, vimos que há poucas iniciativas que se aproximem de preocupações com os aspectos didático-pedagógicos na formação profissional docente. Porém, há possibilidades de se ultrapassar esses caminhos e realizar encaminhamentos que possam, de alguma forma, suprir as necessidades formativas dos licenciandos. Algumas universidades têm criado alternativas para o estágio curricular supervisionado, podendo-se destacar as experiências propostas pela Universidade Federal de São Paulo - UNIFESP (Residência Pedagógica), Universidade Estadual Paulista - Campus Rio Claro - UNESP/RC (Parceria Intergeracional e Formação Docente) e Universidade de São Paulo - USP/Ribeirão Preto (Educadores) no curso de Licenciatura em Pedagogia. Há também as perspectivas de estágio que foram apresentadas nos Encontros Nacionais de Didática e Práticas de Ensino - ENDIPE de 2008 e 2010.

No programa desenvolvido pela UNIFESP, encontramos uma 
vivência semelhante à da medicina. A Residência Pedagógica, que ocorre na Universidade Federal de São Paulo, é uma modalidade especial de estágio curricular baseada na "[...] imersão dos residentes (estagiários) em vivências sistemáticas e temporárias nas práticas pedagógicas de docentes e gestores escolares profissionais" (GIGLO, 2010, p. 376). Os estudantes acompanham a prática pedagógica docente e a política educativa da escola pública, podendo conhecer a gestão da escola e da sala de aula, conhecem o contexto e as relações entre famílias e escola, e entre escola e comunidade (território), preparam um pré-projeto de intervenção com o acompanhamento do professor universitário e do professor que o acompanha na escola; por fim, partem para a intervenção (GIGLIO, 2010).

A Residência Pedagógica (PRP) tem início no quinto semestre do curso, cumprindo os estágios curriculares obrigatórios na Educação Infantil, Ensino Fundamental, Educação de Jovens e Adultos e na Gestão Educacional, sendo que, nos quatro primeiros semestres do curso, os alunos realizam a disciplina Práticas Pedagógicas Programadas (PPP), na qual, ao longo desse período, os discentes se dividem em pequenos grupos e vivenciam, dentro de outras disciplinas, situações que os aproximam da realidade escolar e educacional. Esse programa transforma "[...] os estágios tradicionais numa oportunidade de renovação da formação inicial e continuada de docentes e gestores escolares, e no estabelecimento de novas relações entre as escolas públicas e a Universidade" (GIGLIO, 2010, p. 389).

diferencial do programa está na imersão dos residentes nas escolas por um mês ininterrupto para a realização dos estágios de Educação Infantil e Ensino Fundamental e quinze dias seguidos na Educação de Jovens e Adultos, tendo como meta, além da formação inicial, a formação continuada dos professores das escolas que acompanham os residentes. Estes, assim como os gestores, são vistos como colaboradores no processo de formação (UNIFESP, 20111 . Dessa forma, nessa universidade, está em desenvolvimento no Curso de Pedagogia uma metodologia para a Residência Pedagógica "[...] como uma política de formação inicial de docentes capaz de atuar de maneira propositiva em ambientes escolares, gerando aprendizagens e provocando a revisão das práticas de educadores e gestores já profissionais" (GIGLIO, 2010, p. 376377).

Podemos observar também a experiência realizada na UNESP, campus Rio Claro. Nomeada de Parceria Intergeracional e Formação Docente (SARTI, 
2008; 20091, a proposta em andamento visa colocar em contato professores experientes com estudantes de Pedagogia, para que, através da troca de experiências, ocorra formação continuada e inicial respectivamente.

Os professores em exercício são chamados a desempenhar o papel de iniciadores de uma nova geração docente, algo que thes possibilita vivenciar novas aprendizagens, ao mesmo tempo que sentimentos de valorização de seus saberes e práticas profissionais (SARTI, 2009, p. 134).

Cabe ressaltar que, nesse programa, os professores da escola não são considerados tutores, ou seja, não têm "[...] responsabilidades institucionais comumente associadas a esse papel [...]" (SARTI, 2009, p. 136), mas assumem a postura de parceiros na aprendizagem da docência. Os professores das escolas são convidados a receber estagiários, não havendo seleção prévia para tal.A novidade, nessa proposta, é a elaboração de um projeto pedagógico e do relatório de estágio em parceria, ou seja, professor da escola e estudante preparam as aulas e o relatório final em conjunto. Este último apresenta um cunho reflexivo, no qual o estudante e docente percorrem o caminho de suas 94 experiências para a teoria.

Os professores-colaboradores também têm à sua disposição um curso de extensão oferecido pelo professor-supervisor mostrando o que é e qual a importância do estágio na formação inicial. Essa proposta está em construção, com novos encaminhamentos para o ano de 2013, como por exemplo, a preocupação com o envolvimento da gestão escolar também vista como formadora dos estagiários.

Com relação à USP, campus Ribeirão Preto, os estagiários realizam sua prática na gestão, Educação Infantil e Ensino Fundamental I. Nessa perspectiva de formação, há uma iniciativa que visa à aproximação dos professores da escola com os estagiários, tendo como objetivo dessa aproximação o diálogo e a troca de experiências, entre aquele que está passando pelo choque da realidade, e aquele que está inserido, nessa há algum tempo. O diferencial desse programa é a contratação dos Educadores (técnicos em nível superior, que possuem formação em licenciatura e realizam a mediação entre escola e universidade) por meio de concurso, tendo, dentre suas tarefas a "[...] incumbência principal acompanhar os alunos na realização de seus estágios" (CORREA, 2009, p. 9). 
Outras experiências brasileiras foram encontradas a partir dos Encontros Nacionais de Didática e Prática de Ensino (ENDIPE), que ocorrem, bienalmente, desde a década de 80 , sendo cada edição em uma universidade localizada em diferentes estados do Brasil.Até o ano de 2012, ocorreram 16 encontros. Para o presente, encontramos, nos anais dos ENDIPE (2008 e $2010)$, experiências diferenciadas de estágio que envolveram a escola como um espaço possível de formação. Uma breve análise foi feita com base nos trabalhos encontrados, com a leitura de seus resumos, e, quando necessário, do texto completo. Nessa garimpagem, emergiram algumas experiências que chamaram a atenção, envolvendo o professor-colaborador e/ou tentaram aproximar a escola da universidade.

O XIV ENDIPE (2008) privilegiou a discussão dos diferentes lócus de ensino e aprendizagem. Especificamente sobre a relação da escola com a universidade, encontramos textos que seguem as seguintes temáticas: direção e supervisão da escola e o estágio (SCHEIN, 2008); o Papel do Professor Formador (AZEVEDO; ABIB, 2008); colaboração universidade e escola (AROEIRA, 2008); modelo de formação profissional (BORGES, 2008), bem como os modos diferenciados de se realizar o estágio supervisionado, como a Parceria Intergeracional (SARTI, 2008), citada anteriormente; Residência Pedagógica - Rio de Janeiro (GONZAGA, 2008); Estágio como mediação (YAMIN; RODRIGUES; SILVEIRA, 2008). Os dois últimos serão expostos a seguir.

Gonzaga (2008, p. 5) nos apresenta a experiência da Residência Pedagógica na Universidade Estácio de Sá - Rio de Janeiro baseada na perspectiva da colaboração entre escola, professores, universidade e estagiários "[... ] visando à construção de uma convivência harmônica em que cada um tem seu lugar, com suas escolhas epistemológicas, suas crenças, atitudes e estilo". Nessa pesquisa, a autora aponta que a Residência Pedagógica é um espaço de aprendizagem e reflexão do estagiário, apontando como objetivos: "[...] colocar o aprendiz em contato com a realidade profissional, [...]; integrar teoria e prática, $[. .$.$] ; perceber que o conhecimento nem sempre precisa ser adquirido$ numa lógica ou sequência racional" (GONZAGA, 2008, p. 6).

Outra proposta diferenciada fala sobre o estágio como mediador da teoria com a prática (YAMIN; RODRIGUES; SILVEIRA, 2008). Esse trabalho foi desenvolvido na Universidade Estadual de Mato Grosso do Sul, curso de Pedagogia, tendo como foco o estágio de Educação Infantil. Os estágios foram 
desenvolvidos pelos estudantes em duplas, facilitando a orientação por parte dos supervisores de estágio: "[...] a organização dos estagiários em duplas favoreceu o processo de mediação, pois todos os alunos atuaram em uma mesma instituição, com concentração simultânea de datas e de horários, facilitando a participação das docentes da UEMS" (YAMIN; RODRIGUES; SILVEIRA, 2008, p. 5).

Além disso, o estágio segue uma organização de três etapas, que compreende: "[...] vivência do cotidiano de uma sala de educação infantil durante dois meses [...]"; "[...] intervenção de uma hora de duração, duas vezes por semana [...]"; e "[...] momentos da regência na sala de educação infantil (32 horas), desenvolvendo um Projeto, com acompanhamento das docentes da UEMS" (YAMIN; RODRIGUES;SILVEIRA, 2008, p. 6).Após cada um desses momentos, as autoras acrescentam que eram realizadas reuniões coletivas com os estagiários, o que permitia "[...] o repensar das atividades para o próximo dia de trabalho" (YAMIN; RODRIGUES; SILVEIRA, 2008, p. 6).

Já o XVI ENDIPE (2010) abordou o campo da formação e do trabalho docente. Encontramos trabalhos sobre: Envolvimento ou importância do Professor-colaborador (DIÓGENES; HOLANDA, 2010; CARVALHO; LIMA, 96 2010); Parceira/vínculo universidade e escola (DOMINGUES; AROEIRA; ALVES, 2010 ; DOMINICK; SANTIAGO; FERREIRA, 2010); Relação com a escola (AGOSTINI; SOUZA; LIMA, 2010) e Residência Pedagógica (COSTA, 2010; GIGLIO, 2010). Há outros trabalhos que abordam tais temáticas, porém, para o momento, estes ganham destaque.

Na experiência do NEST (Núcleo de Estágio da Fundação Municipal de Educação de Niterói), Dominick, Santiago e Ferreira (2010),assinalaram que ele é o responsável por estabelecer o vínculo entre as instituições de ensino superior e as escolas. Os autores apontam que ambas as instituições têm ficado, cada vez mais, próximas e complementam que, a partir de 2009, o NEST é responsável por encaminhar os estagiários e pesquisadores às escolas e, ao término de suas atividades, solicitam um relatório do que foi realizado. $\bigcirc$ núcleo de estágio faz "[...] um mapeamento desses relatórios, em consonância com os padrões éticos, buscando possibilidades e dificuldades encontradas nas realidades pesquisadas e socializando esses dados paras as equipes da FME que acompanham as escolas" (DOMINICK; SANTIAGO; FERREIRA, 2010, p. 21 1). Para os autores, a ideia central da ação do NEST "[...] ultrapassa o viés burocrático pelo qual normalmente é entendido o setor pela maioria das 

(DOMINICK; SANTIAGO; FERREIRA, 2010, p. 15).

Em outro trabalho, a pesquisa de Costa (2010) complementa os estudos de Giglio (2010), apresentado anteriormente, na medida em que traz as opiniões de estagiários e docentes escolares com relação ao programa de Residência Pedagógica desenvolvido na UNIFESP. Os participantes da pesquisa avaliam o programa de forma positiva, destacando sua importância para a formação de ambos os grupos (estudantes e docentes). Para a autora, o programa de Residência Pedagógica "[...] possibilitou além de uma aproximação entre a teoria acadêmica e a prática docente, uma nova forma de relação entre elas [...]", além de contribuir "[...] com subsídios importantes para o favorecimento da constituição da identidade docente, tanto dos estudantes do Curso de Pedagogia da Unifesp, quanto dos educadores/ professores da rede municipal" (COSTA, 2010, p. 10).

Dessa forma, as experiências nacionais, dentre outras, apresentadas avançam no sentido de oferecer um diálogo mais efetivo entre teoria e prática, além de estabelecer relações mais próximas com a escola e oferecer possibilidades de um trabalho em conjunto, no qual a universidade e a instituição escolar estão envolvidas com o processo de formação.Apesar dessaspropostas, sabemos que, enquanto espaços privilegiados de diálogo entre teoria e prática, os estágios curriculares enfrentam um duplo desafio: de um lado é necessária uma "[...] revisão dos formatos, garantindo o tempo e as condições adequadas para o contato qualificado dos estudantes com professores e escolas [...]"; por outro lado, é indispensável questionar "[...] o grau de interação existente entre as instituições formadoras e as instituições estagiadas [...]" e "[...] a capacidade de diálogo entre os saberes destas duas instituições e entre os profissionais que nelas atuam" (GIGLIO, 2010, p. 379).

\section{O contexto internacional do estágio supervisionado na docência}

As experiências relacionadas aos Estados Unidos, Canadá, França, Inglaterra e Portugal nas quais encontramos elementos que se colocam como avanços tanto na prática do estágio como na formação de professores, dentre outras, de forma resumida, nos oferecem outras leituras. 
Nos Estados Unidos, há dois tipos de programas de formação de professores: aqueles que seguem uma linha Tradicional (Traditional route program), sendo um curso universitário de quatro anos centrado no ensino; e aqueles que seguem a chamada rota Alternativa (Alternative route program) com foco na maneira como os alunos aprendem e nos métodos eficazes de ensino, visando preparar professores especialistas provenientes, geralmente, dos cursos de bacharelado. Nesse país, os estados podem escolher o programa que vai formar e preparar seus professores, dando prioridade aos programas alternativos (U.S. DEPART. OF EDUCATION, 2009).

No âmbito dessa compreensão, Diniz-Pereira (2008) apresenta a experiência da Universidade de Wisconsin-Madison com a formação dos futuros professores no que tange à elaboração dos estágios, envolvendo os professores supervisores da universidade e professores tutores das escolas. Os tutores se apresentam à universidade mostrando sua intenção em receber estagiários. Eles são selecionados para a função e recebem um pró-labore em dinheiro para exercer o papel de formador; enquanto que os supervisores contam com o auxílio de professores assistentes (Teacher Assistant), alunos de pós-graduação da universidade que trabalham junto ao professor supervisor em 98 um período temporário, recebendo um salário e tendo suas mensalidades do curso dispensadas por esse período.

Os estagiários têm um contato intenso com as escolas de educação básica, desde o primeiro semestre do curso. $\bigcirc$ diferencial desse programa é a existência das "escolas de desenvolvimento profissional" (Professional Development School), que, mesmo se tratando de escolas públicas e particulares, funcionam "[...] como espaços especialmente voltados para a formação de professores, não dicotomizando formação inicial e continuada e trabalhando de uma maneira mais orgânica com a Universidade" (DINIZ-PEREIRA, 2008, p. 263-264).Embora haja essa compreensão, Zeichner (2010, p. 481 ) aponta como impasse que esses supervisores são originários de vários países e sendo assim "[...] eles, com frequência, não estão familiarizados com as escolas locais".

Em outra experiência, Universidade do Estado de Michigan, há uma parceria entre governo, setor privado e educadores com o programa Teacher Education Model for the 21 st Century para preparar professores para todos os níveis de ensino em um curso com duração de cinco anos. Os estudantes realizam uma formação profissional de dois anos; depois, entram em um 
programa de estágio de um ano na escola, acompanhados por professores da universidade. Durante esse período, os futuros professores continuam em um curso acadêmico na universidade e são supervisionados pelos professores universitários, enquanto são lentamente introduzidos na prática junto a um professor-tutor (STUART; TATTO, 2000).

No Canadá, Quebec, podemos encontrar a valorização do professor da escola como formador de futuros docentes a partir da contratação de professores associados ${ }^{2}$, os quais, além de uma formação oferecida pela universidade, recebem um auxílio financeiro para orientar estagiários na sala de aula, como parte de seu trabalho.Essa iniciativa ocorreu no princípio dos anos 90, quando o Ministério da Educação do Quebec (MEQ $\left.{ }^{3}\right)$ propôs uma reforma para a formação de professores: adição do quarto ano de graduação e 700 horas de estágio distribuídas nos quatro anos. OMEQ investiu nas escolas visando acompanhar os estágios nas tarefas de recepção, supervisão, avaliação dos formandos e formação de professores e professores associados (LACROIX-ROY; LESSARD; GARANT, 2003; QUEBEC, 2002).

Essas reformas originaram programas de formação oferecidos em doze universidades do Quebec. Todas as universidades têm autonomia para desenvolver os programas de formação respeitando o que é estabelecido pelo comitê de credenciamento dos programas de formação de professores (CAPFEComitê d'Agrément dês Programmes de Formation à l'Enseignement), formado por representantes da escola e da universidade (GERVAIS; DESROSIERS, 2005). A formação em alternância ocorre entre o meio universitário e o meio escolar, oferecendo períodos em que se trabalha mais a teoria em sala de aula e períodos em que se destina a prática vinculada às escolas aos formandos. Os estudantes de licenciatura iniciam suas atividades práticas no primeiro dia letivo de aula da escola, e permanecem, nesse ambiente, em grupos, por um período de 14 à 16 semanas. Algumas mudanças ocorridas, nesse sentido, visaram priorizar a experiência prática na escola em concomitância com a universidade (KORTHAGEN; LOUGHRAN; RUSSELL, 2006).Assim, quando finalizam a formação, os professores recebem um certificado contendo uma concessão para ensinar (fato que anterior a essa reforma não ocorria) e permanecem em estágio probatório em seus dois primeiros anos de experiência, com a supervisão de um professor experiente.

Gervais e Desrosiers (2005) nos afirmam a importância da escola como lócus de formação, mostrando a responsabilidade social desta na formação dos 
estagiários, bem como sua parceria com a universidade. Nessa relação, vários atores estão envolvidos, estando o estagiário no centro: professores associados (escola), membros da direção, supervisores (universidade), outros membros da equipe escolar, e colegas estagiários.

Como exemplo dessa proposta, na área da Educação Físicalsendo similar para a Pedagogia), há um programa de formação de professores na Universidade de Montréal que procura atender às exigências feitas pelo MELS. Nessa instituição,o currículo, centrado no modelo acadêmico,foi substituído pelo modelo profissional de formação. $\bigcirc$ antigo modelo compreendia a formação do profissional enquanto um tecnólogo, "[...] que domina um conjunto de conhecimentos formalizados e oriundos da pesquisa [...]" com o intuito de aplicá-los na prática escolar (BORGES, 2008, p. 161); os estágios ocorriam no final do curso com uma duração não muito longa, sendo controlados pela universidade. Dessa forma, "[...] os professores que recebem os estagiários se limitam a dar conselhos partilhar sev espaço de trabalho e não participam nem mesmo da avaliação dos estagiários" (BORGES, 2008, p. 161).

Mas, no atual modelo profissional de formação,passou a ter como ênfase: o profissional reflexivo "[...] que produz saberes e que é capaz de 100 deliberar sobre sua própria prática" (BORGES, 2008, p. 161); a prática como centro, contemplando um modelo de estágio em alternância que ocorre ao longo da formação; a escola se tornou o lócus de formação do futuro professor e passou a envolver vários atores, como os "[...] professores associados lou tutores, ou mestres de estágio) [...]", "[...] diretores, especialistas e técnicos de ensino, supervisores" (BORGES, 2008, p. 161).

Assim, os estágios ocorrem desde o início da graduação, com o objetivo de inserir, gradualmente, o licenciando no meio escolar "[...] indo da familiarização e assistência à regência de classe propriamente dita [...]", além de contar com o professor associado (titular da escola) que acolhe os estagiários e possui responsabilidades sobre eles (BORGES, 2008, p. 157).

A formação de professores na França também passou por uma reforma nos anos 90. No início dessa década, foram criados os Institutos Universitários de Formação dos Professores (Instituts Universitaires de Formation dês Maîtres IUFM) localizados em diversas cidades (online ${ }^{4}$ ). Os IUFM tendiam a agir dentro das universidades, tendo como premissa a formação inicial e/ ou continuada de professores que pretendem ou trabalham desde o ensino primário, o ensino geral, 
até o ensino secundário, com disciplinas específicas (online). Os formandos têm contato com as disciplinas teóricas das ciências da Educação, e, em seguida, iniciam os estágios de observação, prática acompanhada e, posteriormente, o "estágio em responsabilidade". Nesse sistema, os aprendizes passavam pelos três ciclos da escola primária (LACOSTE; LOARER; MONNANTEUIL, 2007).

Nesse contexto, na observação,o estagiário confronta a realidade na qual irá atuar examinando a prática de um professor experiente. Na prática acompanhada, o aprendiz se insere por 108 horas no desenvolvimento das atividades práticas da sala de aula, com a presença e supervisão do professor responsável pela classe (online). Há também o estágio em responsabilidade (remunerado - online ${ }^{5}$, visando à formação em alternância: os estagiários vão à escola durante 108 horas, e uma vez por semana ficam responsáveis pela classe; a seguir realizam dois estágios agrupados em um período de três semanas cada, quando o formando oferece suporte para a classe de um professor titular. Nessesistema, os aprendizes passam pelos três ciclos da escola primária (LACOSTE; LOARER; MONNANTEUIL, 2007). Assim, além das atividades práticas, esse tipo de estágio conta com uma análise da compreensão sobre a prática profissional, reflexão sobre o trabalho e a disciplina a ensinar, bem como acompanha a aquisição de conhecimentos da ciência necessários ao exercício da atividade de ensino. Portanto, a formação para o ensino e a formação teórica devem ocorrer de forma simultânea (SEPTOURS; GAUTHIER, 2003).

Em 2010, os IUFM passaram pela reforma denominada de Masterisation, incluindo o nível mestrado na formação de professores. Essa reforma advinda do Processo de Bolonha estabeleceu uma política comum de formação de professores para os países que fazem parte da União Europeia. Segundo esse Processo, além da unificação da formação superior dos países da União Europeia, para a formação docente, é previsto que todos os professores sejam qualificados em nível de mestrado para exercer a profissão. Essa política valoriza aspectos na formação que julgamos necessário ser destacados: a aquisição do conhecimento relativo às disciplinas a ensinar, sobretudo na preparação do professor generalista; a fundamentação da prática de ensino na investigação, e a iniciação à prática profissional em contexto escolar. Dessa forma, para a aprendizagem da prática profissional, a União Europeia (BRUXELAS, 2007) estabeleceu a parceria entre instituições de ensino superior e escola, sendo este, dentre outros, um princípio comum que todos os países 
devem seguir, realizando as adaptações para cada realidade.

Porém, em 2012, a França passou por uma nova reforma, substituindo os IUFM pelas Écoles Supérieures Du Professoratet de l'Education (Escolas Superiores do Professorado e da Educação - ESPEל). As ESPE visam a uma formação com forte dimensão profissional em nível mestrado. Participam tanto da formação inicial docente, quanto da formação continuada do professorpesquisador do ensino superior (online ${ }^{7}$, ou seja, formam desde professores da escola maternal até os professores do ensino superior. Partem do princípio de que os profissionais da educação "devem aprender progressivamente em um processo integrado de uma parte de saberes teóricos e de saberes práticos fortemente articulados uns aos outros, e de outro lado os períodos de estágio em situação ${ }^{81}$ (online) $)^{9}$.A formação prática, na forma de estágios curriculares, é plenamente integrada na formação, mantendo uma relação próxima com um tutor no interior da instituição escolar que tem como função supervisionar e acompanhar os estagiários. Além disso, os estágios devem ter origem em um tempo de preparação e a uma fase de exploração e de análise reflexiva.

Em Portugal, há uma política nacional de formação de professores que também está diretamente ligada ao Processo de Bolonha. Nesse país, 102 a formação inicial de professores se dá com três anos de licenciatura (nível de graduação) e dois anos de mestrado, com caráter profissionalizante. No Decreto-Lei n. 43/2007, podemos destacar que

Com a transformação da estrutura dos ciclos de estudos do ensino superior, no contexto do Processo de Bolonha, este nível será agora o de mestrado, o que demonstra o esforço de elevação do nível de qualificação do corpo docente com vista a reforçar a qualidade da sua preparação e a valorização do respectivo estatuto sócioprofissional (PORTUGAL, 2007a, p. 1320).

Para os formandos a professores, o currículo é organizado da seguinte maneira nos Mestrados em Ensino: "[...] as componentes de Formação educacional geral (25\%), Didácticas específicas (25\%), Iniciação à prática profissional, incluindo a prática de ensino supervisionada (40\%) e Formação na área de docência (5\%)" (CLAUDINO, 2011 , p. 26). Ao final do curso de mestrado,os futuros professores devem apresentar uma dissertação acerca de sua iniciação à prática profissional.

Encontramos também alguns exemplos diferenciados de estágios na 
Austrália. No relatório "[...] Teachers for the Future - The Changing Natureof Societyand Relatedlssues for the Teaching Workforce" (SKILBECK; CONNELL, 2004 , p. 45), os autores citam inovações de parcerias entre universidade e escola na formação inicial de professores em diversas universidades, das quais predominam a formação no mestrado. Ao mesmo tempo que reconhecem a importância da escola enquanto espaço de formação, enfrentam dificuldades com relação à participação ativa destas na inserção de estagiários.

Na Holanda, na Universidade de Utrecht, há a iniciativa de se estabelecer uma colaboração entre universidade e administração da escola. Os estagiários vão à escola durante quatro meses, podendo ministrar suas aulas individualmente após esse período por outros quatro meses, quando ele fica com total responsabilidade pela sala de aula. Os estudantes são supervisionados a distância por tutores e o acompanhamento é praticamente baseado na reflexão e experiência do aluno, sendo imprescindível para realizar a ponte entre teoria e prática (KORTHAGEN; LOUGHRAN; ROUSSELL, 2006).

Tanto na Austrália quando na Holanda, observamos que nos programas citados, os formadores de professores compreendem que a prática não é uma forma de aprendizado, mas sim a reflexão desta e a interação com o outro.

Na Inglaterra, a formação de professores também passou por três principais reformas durante o século XX, assim apresentadas por Moon (2008): florescimento da tradição progressista fundamental (1900-1970); esperança e expansão (1970-1985) e; desilusão e contração (1 985-2000). Em cada uma dessas etapas, observamos uma tensão e uma preocupação no que diz respeito à formação prática ou teórica dos professores, local onde serão formados, quem valida ou certifica essa formação.

Nessas tensões, Moon (2008) assinala que três aspectos foram bem aceitos: a noção de parceria entre as escolas e os formadores de professores; o conceito de que os docentes escolares são mentores dos estagiários e; avaliação dos professores em período probatório a partir de um quadro de competências. $O$ primeiro aspecto é bem recebido pelos licenciandos, sendo que é,nessa relação, que se constitui a "qualidade da experiência" (MOON, 2008, p. 107). É proposta aos professores da escola (experientes), a participação no planejamento e instalação do programa de formação na instituição escolar. Nesse caso, os docentes da escola atuam como 'mentores', recebendo uma formação da universidade a qual destaca o papel que devem 
desenvolver. Segundo Moon (2008, p. 108), "[...] o apoio prestado pelos docentes aos seus colegas em formação é uma prática tradicional [...]" no país.

Assim, os professores experientes das escolas participam da avaliação final dos recém-formados, sendo essas responsabilizadas por boa parte da formação dos futuros professores, pois é de compreensão do governo que as escolas estão mais bem colocadas para ajudar os futuros docentes no desenvolvimento de técnicas de ensino prático (EDWARDS, 1995).

Um exemplo concreto que ocorre tanto na Inglaterra como no País de Gales, é o Bachelorof Education Program (B.Ed), curso de graduação exigido para quem deseja ser professor do ensino primário. Nesses países,ocorre a elaboração de um currículo nacional para a formação de professores ("The National Curriculum for TeacherEducational") visando à preparação destes para as escolas primárias e secundárias financiadas pelo governo (STUART; TATTO, 2000l.O curso possui um currículo composto por conhecimentos e compreensões de matérias pedagógicas juntamente com provas práticas de ensino. A principal característica desse programa é que, pelo menos, 50\% dele está vinculado a uma base escolar.

Em ambos os países, os alunos-mestres passam por diferentes fases durante o estágio: a fase 1 corresponde ao momento de se aprender conceitos, explorá-los e compartilhá-los; na etapa 2, eles definem uma tarefa prática e a realizam; a fase 3 existe para que os alunos discutam a tarefa realizada e façam conexões; nos passos 4 e 5, os estudantes devem verificar o que foi aprendido através da prática em sala de aula. Edwards (1995) aponta que, durante essas etapas, os alunos-mestres estão em constante diálogo com os professores-colaboradores da escola.

Com base nas experiências internacionais, o que observamos foi a centralidade dada à escola na formação dos futuros docentes, sendo que, em boa parte, a escola toma para si a responsabilidade formal de iniciá-los no ambiente profissional.Esse pressuposto é apontado por Canário (2000), na medida em que reconhece esse espaço como formador de professores profissionais, ou seja, o autor anuncia...

[...] que as escolas sejam encaradas como os lugares fundamentais de aprendizagem profissional e não como meros lugares de "aplicação". A aceitação deste pressuposto implica que os contactos estreitos com os contextos de trabalho sejam o mais 
precoces possível e estejam presentes ao longo de todo o percurso de formação inicial, não se circunscrevendo a uma etapa final. Só desta forma é possível favorecer um percurso iterativo entre formação e trabalho que permite o movimento duplo de mobilização, para a acção, de saberes teóricos, e, ao mesmo tempo, a formalização (teórica) de saberes adquiridos por via experiencial (CANÁRIO, 2000, p. 131.

Nos países apresentados, há em destaque a figura do professor da escola ocupando um espaço essencial no desenvolvimento profissional docente, sendo reconhecido, formalmente, como formador de futuras gerações docentes.

\section{Considerações finais}

Nós poderíamos concluir este texło dizendo que o grande desafio do Estágio Curricular Supervisionado está em fazer do ensino uma atividade profissional e não uma atividade artesanal ou decorativa. Essa compreensão envolve a noção de que a formação de professores deve ter como referência o trabalho docente. Caso contrário,expressões do tipo "na prática, a teoria é outra", "o professor se torna professor, sendo professor" e,assim por diante, continuarão sendo perpetuadas.

Gauthier, Martineau, Malo e Simard (1998) nos provocam sobre o assunto ao colocar sobre o paradoxo da Pedagogia: "ofício sem saberes" e "saberes sem ofício". Antes não se tinha um corpo de saberes que fundamentassem o ofício de ensinar (ofício sem saberes), mas, a partir das Ciências da Educação, se criou esse corpo de fundamentação desvinculado do exercício profissional, prática profissional (saberes sem ofício), constituindose,também, em outro desafio: dar uma identidade para essa área.

Dessa forma, no presente texto, que expõe o Estágio Curricular Supervisionado em diferentes contextos a partir de uma pesquisa bibliográfica e documental, buscamos apresentar como fio condutor a dimensão profissional de formação.

E o que tal dimensão representa? $\bigcirc$ que está por trás da ideia de formação profissional? $\bigcirc$ que as diferentes experiências e realidades encontradas nos apontam em termos de Estágio Curricular e Prática de Ensino? Qual é o lugar que a prática ocupa no processo de estágio? E a relação 
universidade e escola?

Neste trabalho, essas questões, entre outras, podem ser organizadas em torno de quatro pontos complementares e interligados: (a) A relação Universidade e Escola mediada pelo Modelo de Formação; (b) Os Professores de Escola como Formadores; (c) A Política Docente de Formação de Professores e; (d) O Estágio Curricular e a Prática de Ensino como uma área de conhecimento emergente e complexa.

Observamos que a profissionalização do ensino apresenta uma conexão muito significativa com à epistemologia da prática sugerida por Schön (2000), em contraposição a epistemologia da racionalidade técnica vinculada, muitas vezes, ao modelo acadêmico de formação. Nessa direção, pensar a relação universidade e escola significa pensar também no modelo de formação que está engendrando esse processo. No modelo acadêmico, o processo está centrado no conhecimento científico, enquanto que, no modelo profissional, é a escola e a prática que ganham destaque, dando margem à participação de outros atores sociais.

A experiência do Canadá, bem como da França concebem não só a escola como lugar de formação, mas também uma epistemologia da prática profissional como fundamento desse processo. Nas outras experiências internacionais, a escola, enquanto lugar de formação, é uma realidade, embora haja também as exceções.

Porém, no Brasil, nós temos um discurso sobre a formação, a escola e o estágio, padecendo na dimensão crítica, muitas vezes acrítico ao não tratarmos de fato da formação de professores. Da mesma forma que padecemos em não considerar a prática e a prática profissional como um lugar de formação e de produção de conhecimento. Nesse sentido, o desafio consiste em uma mudança de mentalidade que, de fato,considere esses espaços como lugares de formação.

No modelo profissional de formação ou no modelo perspectivado pela profissionalização do ensino, emerge a figura do formador, ou tutor e/ ou mentor. Neste trabalho, nós atribuímos destaque para a categoria do formador, denominado como professor-colaborador, professor associado, professor-cooperante, professor parceiro etc. Entretanto, a figura do professor formador não existe na realidade brasileira se comparada com a experiência francesa, canadense ou americana em função de que recebem uma formação 
específica para exercer essa função, ganhando um grau de distinção na cultura pedagógica. Ser um professor formador significa ser um expert no campo do ensino, significa que é alguém que domina o conhecimento pedagógico/ didático do conteúdo específico (SHULMAN, 1987). Portanto, é alguém que sabe ensinar a ensinar, que possui "saberes para ensinar" e "saberes a ensinar" (PERRENOUD, 2001).

Assim, há necessidade de que, na política docente brasileira, seja concedido um espaço para a seleção e preparação desses professores para essa função, além de reconhecimento na carreira docente. Embora nos normativos legais voltados para a formação de professores a docência seja a base dessa nova construção identitária, ela pode não ter o lugar que the cabe no processo de formação.

ensino é uma atividade complexa, pois a natureza do objeto do trabalho é: humana; individual e social; heterogênea; ativa e capaz de oferecer resistência; comporta uma parcela de indeterminação e de autodeterminação (liberdade); não pode ser analisado e nem reduzido aos seus componentes funcionais em função de que "[...] o produto do trabalho é intangível e imaterial", podendo dificilmente "[...] ser observado, medido" (TARDIF, 2002, p. 124-125). Porém, o ensino é algo sério e não podemos mais continuar improvisando na formação de professores. Chegou o momento de transformar o discurso em ação, a Prática de Ensino em objeto de estudo e a pesquisa e a formação assumirem, de fato, a docência como a base dessa identidade. Do mesmo modo, os professores de estágio da universidade precisam também profissionalizar-se e trabalhar em conjunto com os professores de escola, colocando o Estágio Curricular e a Prática de Ensino como centro do processo de formação.

\section{Notas}

1 Parecer CNE/CP 28/2001; Resolução CNE/CP 2/2002.

2 Professores que recebem estagiários em sua sala de aula, na escola.A nomenclatura "professor associado" é utilizada em todos os programas de formação do Quebec.

3 Atualmente Ministère de l'Éducation Loisir et Sport Du Quebec (MELS).

4 Cf. http://www.iufm.fr

5 Cf. http://www.education.gouv.fr 
estágio curricular supervisionado na experiência brasileira e internacional

6 Cf. http://espe.u-pec.fr/l-espe/presentation/de-la-masterisation-a-aujourd-hui/la-masterisation-505007.kisp

$7 \mathrm{http}: / /$ www.enseignementsup-recherche.gouv.fr/cid72789/espe-tout-savoir-sur-les-ecoles.html

8 Tradução nossa.

9 http://www.enseignementsup-recherche.gouv.fr/cid72790/espe-une-formation-a-forte-dimension-professionnelle-reconnue-par-un-diplome.html.

\section{Referências}

AGOSTINI, Sandra; LIMA, Maria Socorro Lucena; SOUSA, Ana Lourdes Lucena. O Estágio Supervisionado na Formação de Professores: múltiplos olhares. In: ENCONTRO NACIONAL DE DIDÁTICA E PRÁTICA DE ENSINO (ENDIPE), 15., 2010, Belo Horizonte. Anais... Belo Horizonte: Universidade Federal de Minas Gerais, 2010. 1CD-ROM.

AROEIRA, Kalline Pereira. Saberes e estágio supervisionado: possibilidades e desafios na ação colaborativa entre universidade e escola. In: ENCONTRO NACIONAL DE DIDÁTICA E PRÁTICA DE ENSINO, 14.,2008, Porto Alegre. Anais... Porto Alegre: Pontifícia Universidade Católica de Porto Alegre,2008. 1 CD-ROM.

AZEVEDO, MariaAntonia Ramos de; ABIB, Maria Lúcia Vital dos Santos.O papel do professor formador frente aos cenários educacionais no seu trabalho de orientação de estágios. In: ENCONTRO NACIONAL DE DIDÁTICA E PRÁTICA DE ENSINO(ENDIPE) 14.,Porto Alegre. Anais...Porto Alegre: Pontifícia Universidade Católica de Porto Alegre,2008. 1 CD-ROM.

BENITES, LarissaCerignoni. O professor-colaborador no estágio curricular supervisionado em educação física: perfil, papel e potencialidades. Rio Claro, 2012, 158f. Tese (Doutorado em Ciências da Motricidade) - Programa de Pós-Graduação em Ciências da Motricidade Humana, Universidade Estadual Paulista, Rio Claro, 2012.

BORGES, Cecília. A formação docente em Educação Física em Quebec: saberes espaços, culturas e agentes.In: ENCONTRO NACIONAL DE DIDÁTICA E PRÁTICA DE ENSINO, 14., 2008.Porto Alegre. Anais...Porto Alegre: Pontifícia Universidade Católica de Porto Alegre,2008. 1 CD-ROM.

BRASIL. Decreto-lei n 8.530, de 2 de janeiro de 1946. Lei Orgânica do Ensino Normal. 1946. Rio de Janeiro, 8 de janeiro de 1946. Diário Oficial [da] República Federativado Brasil, Seção 1, 1946. 
. Conselho Federal de Educação. Parecer nº 292, de 14 de novembro de 1962.

Fixa o Currículo Mínimo e a duração do Curso de Pedagogia. Documenta, Brasília, n. 10, p. 95-100, 1962 (Relator Valnir Chagas).

Conselho Federal de Educação. Resolução n. ${ }^{9}$, de 6 de outubrode 1969. Fixa o currículo do curso de Pedagogia. Diário Oficial [da] República Federativa do Brasil, Poder Executivo,Brasília, DF, 6 out. 1969.

Conselho Federal de Educação. Parecer CFE 4.873/75. Formação Pedagógica das Licenciaturas.Documenta, Brasília, v. 181, p. 212, 1975.

Ministério da Educação. Lei n ${ }^{\circ}$ 6.494, de 7 de dezembro de 1977. Diário Oficial [da] República Federativa do Brasil, Poder Executivo,Brasília, DF,9 dez. 1977.

Decreto n. 87.497, de 18 de agosto de 1982. Diário Oficial [da] República Federativa do Brasil, Poder Executivo, Brasília, DF, 18 ago. 1982.

Decreto n. ${ }^{\circ}$ 89.467, de 21 de Março de 1984. Diário Oficial [da] República Federativa do Brasil, Poder Executivo, Brasília, DF, Brasília, 21 mar. 1984.

Lei n 8.859, de 23 de março de 1994. Diário Oficial [da] República Federativa do Brasil, Poder Executivo, Brasília, DF, 23 de março, 1994. Disponível em: http://www. planalto.gov.br/ccivil_03/leis/18859.htm. Acesso em: 6 jul. 2009.

Conselho Nacional de Educação. Lei nº 9394, de 20 de dezembro de 1996. Lei de Diretrizes e Bases da Educação Nacional. Diário Oficial [da] República Federativa do Brasil, Poder Executivo, Brasília, DF,20 dez. 1996. Disponível em: http://www. planalto. gov.br/ccivil_03/leis/19394.htm. Acesso em: 3 jun. 2009.

Conselho Nacional de Educação. Parecer CNE/CES n. ${ }^{\circ}$ 744/97, de 3 de dezembro de 1997. Relatora: Silke Weber. Documenta,Brasilia, p. 2, 1997. Disponível em: hitp:// portal.mec.gov.br/cne/arquivos/pdf/1997/pces744_97.pdf. Acesso em: 5 jun. 2009.

. Conselho Nacional de Educação. Parecer CNE/CP n. ${ }^{\circ}$ 9/200 1, 8 maio, 2001 a. Diário Oficial [da] República Federativa do Brasil, Poder Executivo, Brasília, DF, 8 de maio, 2001 . Seção 1, p. 131. Disponível em: http://portal.mec.gov.br/cne/arquivos/pdf/009. pdf. Acesso em: 7 out. 2009.

Conselho Nacional de Educação. Parecer CNE/CP n. ${ }^{\circ}$ 28/2001, 2 out. 2001 a. Diário Oficial [da] República Federativa do Brasil, Poder Executivo, Brasília, DF, Brasília, DF, 02 de out, 2001 a. Disponível em: http://portal.mec.gov.br/cne/arquivos/pdf/028. pdf. Acesso em: 7 out. 2009. 
. Conselho Nacional de Educação. Resolução CNE/CP 1/2002 18 de fevereiro de 2002. Institui Diretrizes Curriculares Nacionais para a Formação de Professores da Educação Básica, em nível superior, curso de licenciatura, de graduação plena. Diário Oficial [da] República Federativa do Brasil, Poder Executivo, Brasília, DF, 9 abr. 2002. Seção 1.

Conselho Nacional de Educação. Resolução CNE/CP 2/2002 19 de fevereiro de2002a. Institui aduração e a carga horária dos cursos de licenciatura, de graduação plena, de formação de professores da Educação Básica em nível superior. Diário Oficial [da] República Federativa do Brasil, Poder Executivo, Brasília, DF, 4 mar. 2002a. Seção 1, p. 9.

Presidência da República/Casa Civil. Lei nº 11.788, de 25 de setembro de 2008 Brasília: Subchefia para Assuntos Jurídicos, 2008.

BRUXELAS. Comissão das Comunidades Europeias. Melhorar a qualidade da formação acadêmica e profissional dos docentes. Comunicação da Comissão ao Conselho e ao Parlamento Europeu. Bruxelas, 2007.

CANÁRIO, Rui. A prática profissional na formação de professores. Inafop. Formação profissional de professores no ensino superior. Universidade de Aveiro, 2000. Disponível em: http://www.fe.unicamp.br/falaoutraescola/resumos-palestrantes/Rui Canario.pdf. Acesso 110 em: 23 abr. 2012.

CARVALHO, Michelle Barroso de Oliveira; LIMA, Maria Socorro Lucena. Construindo a Docência: Professor e Estagiário na sala de aula. In: ENCONTRO NACIONAL DE DIDÁTICA E PRÁTICA DE ENSINO, 15., 2010, Belo Horizonte. Anais... Belo Horizonte: Universidade Federal de Minas Gerais, 2010. 1CD-ROM.

CLAUDINO, Sérgio. A formação Inicial dos professores portugueses de geografia: por uma recontextualização disciplinar e formativa. Revista Plures Humanidades, Ribeirão Preto, v. 12, n. 15, p. 13-33, jan./jun. 2011 . Disponível em: http://seer.mouralacerda.edu.br/ index.php/plures/article/view/1. Acesso em: 20 jan. 2013.

CORREA, Bianca Cristina.Experiências de estágio em um curso de Pedagogia: vivências e desafios em busca de uma formação de qualidade. In: CONGRESSO INTERNACIONAL CIDINE: Novos contextos de formação, pesquisa e mediação, 2009, Vila Nova de Gaia, Aveiro, Portugal. Anais...Aveiro: Vila Nova de Gaia, 2009.

COSTA, Virginia Fernandes da. Tecendo a formação universitária e contínua no programa de residência pedagógica da Unifesp, Guarulhos.In: ENCONTRO NACIONAL DE DIDÁTICA E PRÁTICA DE ENSINO, 15., 2010, Belo Horizonte. Anais... Belo Horizonte: Universidade Federal de Minas Gerais, 2010. 1CD-ROM. 
CYRINO, Marina. Formaçãa inicial de professores: o compromisso do professor-colaborador e da instituição escolar no processo de estágio supervisionado. Rio Claro, 2012, 233f. Dissertação (Mestrado em Educação) - Programa de Pós-Graduação em Educação, Universidade Estadual Paulista, Rio Claro, 2012.

DINIZ-PEREIRA, Júlio Emílio. A formaçãoacadêmico-profissional: compartilhando responsabilidades entre universidades e escolas. In: EGGERT, Egla; TRAVERSINI, Clarice Salete; PERES, Eliane; BONIN, lara Tatiana. Trajetória e processos de ensinar e aprender: didática e formação de professores. Porto Alegre, EdiPUCRS, 2008.

DIOGENES, Amanda Nunes; HOLANDA, Sofia Cavalcanti Lima de Professores-monitores e o desenvolvimento dos estágios supervisionados: a importância da relação institucional entre escolas e universidades.In: ENCONTRO NACIONAL DE DIDÁTICA E PRÁTICA DE ENSINO, 15., 2010, Belo Horizonte. Anais... Belo Horizonte: Universidade Federal de Minas Gerais, 2010. 1CD-ROM.

DOMINGUES, Isaneide; AROEIRA, KallinePereira;ALVES, Wanderson. Formação e Trabalho na Escola: Olhares e Perspectivas.In: ENCONTRO NACIONAL DE DIDÁTICA E PRÁTICA DE ENSINO, 15., 2010, Belo Horizonte. Anais... Belo Horizonte: Universidade Federal de Minas Gerais, 2010. 1 CD-ROM.

DOMINICK, Rejany dos Santos; SANTIAGO, Solange;FERREIRA, Sueli Camargo. $\bigcirc$ estágio na formação de professores em Niterói - RJ: interações, construções e reflexões.ln: ENCONTRO NACIONAL DE DIDÁTICA E PRÁTICA DE ENSINO, 15., 2010, Belo Horizonte. Anais... Belo Horizonte: Universidade Federal de Minas Gerais, 2010. 1CD-ROM.

EDWARDS, Anne. Teacher education: Partnerships in pedagogy? Teaching and Teacher Education, Oxford, v. 11, n. 6, p. 595-610, 1995. Disponível em: http://www.sciencedirect.com/science/article/pii/0742051X9500015C. Acesso em: 3 ago. 2009.

GAUTHIER, Clermont; MARTINEAU, Stéphane; MALO, Annie; SIMARD, Denis. Por uma teoria da Pedagogia. ljuí: UNIJUÍ, 1998.

GERVAIS, Colette;DESROSIERS, Pauline. L'école, lieu d formation d'enseignants: questions et repères pour l'accompagnement de stagiaires. Laval: Lespresses de l'universitéLaval, 2005.

GIGLIO, Célia Maria Benedicto. Residência pedagógica como diálogo permanente entre a formação inicial e continuada de professores. In: DALBEN, Ângela Imaculada Loureiro de Freitas; DINIZ-PEREIRA, Júlio Emílio; LEAL, Leiva de Figueiredo Viana; SANTOS, Lucíola Licínio de Castro Paixão (Org.).Convergências e tensões no campo da formação e do trabalho docente. Belo Horizonte: Autêntica, 2010. 
GONZAGA, Kátia Valéria Pereira. A residência pedagógica como espaço privilegiado de formação de professores. In: ENCONTRO NACIONAL DE DIDÁTICA E PRÁTICA DE ENSINO, 14.,2008, Porto Alegre. Anais...Porto Alegre: Pontifícia Universidade Católica de Porto Alegre,2008. 1 CD-ROM.

HOLMES GROUP. Tomorrow's teachers: A report of the Holmes Group.East Lansing. Michigan: Holmes Group. 1986.

KORTHAGEN, Fred; LOUGHRAN, John; RUSSELL, Tom.Developing fundamental principles for teacher education programs and practices. Teaching and Teacher Education, Oxford,v. 22, n. 8, 2006. p. 1020-104 1.Disponível em:http://www.sciencedirect.com/science/article/pii/S0742051X06000618. Acesso em: 3 ago. 2009.

LACOSTE, Jean-Pierre; LOARER, Christian; MONNANTEUIL, François. Les stages en responsabilité dans la formation initiale des professeurs. Ministére de la Jeunesse, de l'Éducation Nationale et de la Recherche.Paris (França), 2007. (Rapport IGAENR - Rapport conjoint IGEN-I.G.A.E.N.R. Mars, 2007). Disponível em: http:/ / www.education.gouv.fr/cid5098/ les-stages-en-responsabilite-dans-la-formation-initiale-des-professeurs.html. Acesso em: 24 mar. 2011 .

LACROIX-ROY, Francine; LESSARD, Michel; GARANT, Céline. Étude sur les programmes

112 de formation et l'accompagnement des stagiaires. Canadá:Table MEQ-Universités, 2003. Disponível em: http://www.mels.gouv.qc.ca/. Acesso em: 01 mar. 2011.

LÜDKE, Menga; ANDRÉ, Marli Eliza Dalmazo Afonso de. Pesquisa em educação: Abordagens Qualitativas. São Paulo: EPU, 1986.

MOON, Robert. As políticas reformistas: transição na formação dos professores na Inglaterra. In: TARDIF, Maurice; LESSARD, Claude (Org.). Ofício de professor: história, perspectivas e desafios internacionais. Petrópolis, RJ: Vozes, 2008.

PERRENOUD, Philippe. Ensinar: agir na urgência, decidir na incerteza. Saberes e competências em uma profissão complexa. Porto Alegre: Artmed, 2001.

PORTUGAL. Ministério da Educação/Direcção-Geral dos Recursos Humanos da Educação.

Política de formação de professores em Portugal. Portugal: Notiforma/Touch,2007.

Decreto Lei n 43/2007. Diário [da] República, Portugal, 22 fev. 2007a. 1. A série $\mathrm{n}^{\circ}$ 38. Disponível em: http://www.dges.mctes.pt/NR/rdonlyres/84F15CC8-5CE 14D50-93CF-C56752370C8F/1 139/DL432007.pdf. Acesso em: 17 fev. 2013. 
QUEBEC. Gouvernement du Québec. Ministère de l'Education. Encadrement des stagiaires de la formation à l'enseignement: Rapport d'évaluation de programme. Bibliothèquenationaledu Québec, 2002. Disponível em: http://www.mels.gouv.qc.ca/fileadmin/site_web/documents/publications/EPEPS/Form_titul_pers_scolaire/EncStagiairesRapEval_f.pdf. Acesso em: 5 ago. 2009.

SARTI, Flávia Medeiros. $\bigcirc$ professor formador e as possibilidades da parceria intergeracional na escola. In: ENCONTRO NACIONAL DE DIDÁTICA E PRÁTICA DE ENSINO, 14.,2008, Porto Alegre. Anais...Porto Alegre: Pontifícia Universidade Católica de Porto Alegre,2008. 1 CD-ROM.

Parceria intergeracional e formação docente. Educação em Revista, Belo Horizonte, v. 25, n. 2, ago, 2009. Disponível: http://www.scielo.br. Acesso em: 21 jan. 2010.

SCHIEN, Diana. Um olhar da escola sobre a sua relação com o estágio supervisionado na formação de professores.In: ENCONTRO NACIONAL DE DIDÁTICA E PRÁTICA DE ENSINO (ENDIPE) 14.,2008, Porto Alegre. Anais...Porto Alegre: Pontifícia Universidade Católica de Porto Alegre, 2008. 1 CD-ROM.

SCHON, Donald. Educando o profissional reflexivo. Porto Alegre: Artmed, 2000.

SEPTOURS, Georges; GAUTHIER, Roger-François. La formation initiale et continue des maîtres. Ministére de la Jeunesse, de l'Éducation Nationale et de la Recherche França. Rapportconjoint IGEN-I.G.A.E.N.R. février, 2003. Disponível em: http://www.education. gouv.fr/cid2 1 19/la-formation-initiale-et-continue-des-maitres.html. Acesso em: 24 mar. 2011.

SHULMAN, Lee. Knowledge and teaching: foundations of a new reform. Harvard Educational Review, Cambridge, v. 57, n. 1, p. 1-22, 1987.

SKILBECK, Malcom; CONNELL, Helen. Teachers for the future: the changing nature of society and related issues for the teaching workforce. A report to the teacher quality and educational leadership taskforce of the ministerial council for education, employment training and youth affairs. Austrália, september, 2004. Disponível em: http://www.mceecdya.edu.au/ mceecdya/publications, 1 1582.html. Acesso em: 9 set. 2009.

SOUZA NETO, Samuel. A educação física na universidade: licenciatura e bacharelado - as propostas de formação profissional e suasimplicações teórico-práticas. São Paulo. 1999. 334f.Tese (Doutorado em Educação) - Programa de Pós-Graduação em Educação, Universidade de São Paulo, São Paulo, 1999.

STUART, JanetS.;TATTO, Maria Teresa. Designs for initial teacher preparation programs: an international view. International Journal of Educational Research, v. 33, n. 5, p. 
493-514, 2000, Disponívelem: http://www.sciencedirect.com/science/article/pii/ S0883035500000318. Acesso em: 23 ago. 2009.

TARDIF, Maurice. Saberes docentes e formação profissional. Petrópolis, RJ: Vozes, 2002.

U.S.Department of Education. The secretary's sixth annual report on teacher quality: a highly qualified teacher in every classroom. United Statesof America: Ed Pubs, Education Publications Center, 2009.

UNIVERSIDADE FEDERAL DE SÃO PAULO. Universidade Federal de São Paulo. Manual do Programa de Residência Pedagógica. Departamento de Educação, Universidade Federal de São Paulo, 201 1. Disponível em: http://humanas.unifesp.br/observatorio/resid/prp_ manual_v2011_revclecio.pdf. Acesso em: 11 mar. 2011.

YAMIN, Giana Amaral; RODRIGUES, Almerinda Maria dos Reis Vieira; SILVEIRA, Débora de Barros. A mediação como instrumento fundamental para o trabalho de estágio supervisionado: limites e possibilidades na educação infantil. In: ENCONTRO NACIONAL DE DIDÁTICA E PRÁTICA DE ENSINO, 14.,2008, Porto Alegre. Anais...Porło Alegre: Pontifícia Universidade Católica de Porto Alegre,2008. 1 CD-ROM.

ZEICHNER, Ken. Repensando as conexões entre a formação na universidade e as 114 experiências de campo na formação de professores em faculdades e universidades. Educação. Revista do Centro de Educação, Santa Maria,v. 35, n. 3, 2010. p. 479503,set./dez. 2010. Disponível em: hitp://redalyc.vaemex.mx/src/inicio/ArtPdfRed. isp? iCve $=117116968009$. Acesso em: 7 abr. 2012.

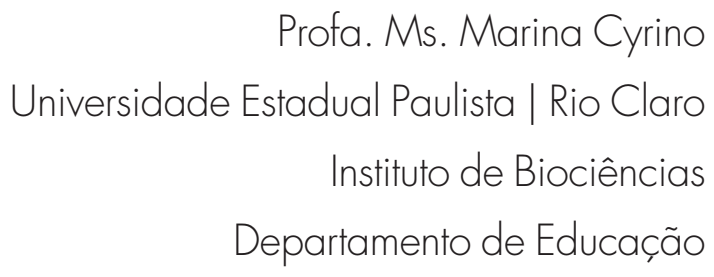

Grupo de Pesquisa Docência, Formação de Professores e Práticas de Ensino | DOFPPEN FAPESP | Fundação de Amparo a Pesquisa do Estado de São Paulo E-mail | ma.cyrino@hotmail.com 
Prof. Livre-DocenteSamuel de Souza Neto

Universidade Estadual Paulista | Rio Claro Instituto de Biociências Departamento de Educação Grupo de Pesquisa Docência, Formação de Professores e Práticas de Ensino | DOFPPEN Núcleo de Estudos e Pesquisas em Educação Física | NEPEF-FPCT E-mail|samuelsn@rc.unesp.br

Recebido 19 fev. 2014 Aceito 6 jul. 2014 